\title{
Predicting the durability of zinc coatings based on laboratory and field tests
}

\author{
Mark Kovalev $^{1 *}$, Ekaterina Alekseeva ${ }^{1}$, Nikita Shaposhnikov ${ }^{1}$, and Anton Povyshev ${ }^{1}$ \\ ${ }^{1}$ Peter the Great St. Petersburg Polytechnic University, 195251 Saint Petersburg, Russia
}

\begin{abstract}
Galvanizing is one of the most common methods of corrosion protection. For the deposition of zinc coatings used such methods as gas-thermal deposition, thermal diffusion saturation in powder, hot-dip galvanizing, cladding, and galvanic precipitating during electrolysis. The hot-dip galvanizing is the most common method, which is used in construction, automotive and other industries. Paper presents the results of research of zinc coatings used in sea conditions. The aim of the work was to determine an acceleration factor by comparing the corrosion rate in laboratory conditions with the data from field tests. Laboratory studies were carried out in a salt fog chamber. Samples were periodically removed from chamber to build the dependence of the corrosion rate on the exposure time. Field tests were carried out at the exploitation area. Result of the work is a guide that allows to predict the corrosion rates of zinc coatings using laboratory tests. The advantage of this test method is shorter time of exposure in comparison with field test.
\end{abstract}

\section{Introduction}

The hot galvanizing method is one of the most common and effective methods corrosion protection method of steel metal structures [1]. This is due to the fact that zinc is the anode to most metals used in corrosive environments. Evaluation the durability of zinc coatings is an actual task due to the widespread use of such coatings. The protective properties of zinc coatings depend on the corrosion resistance of the deposited zinc, therefore, the durability of the coating is determined by its thickness and aggressiveness of the operating conditions [2].

One of the common types of tests for assessing the corrosion resistance of coatings in a marine atmosphere is the salt spray test. Testing in a salt fog chamber, the temperature of which is constantly maintained at $+35^{\circ} \mathrm{C}$, and humidity at $90 \%$, which significantly accelerate corrosion processes. The results obtained during the tests in the salt spray chamber allow us to qualitatively compare different types of coatings, but do not answer the question about the durability of the zinc coating of a certain thickness in real conditions. Field climatic tests make it possible to obtain the most accurate values of corrosion rates. The minimum exposure time of zinc coatings during field tests is 3-5 years. The presence of the results of field tests of zinc coatings allows us to calculate their durability.

Assessment the durability of zinc coating can be incorporated in the regulatory documentation for construction. If the contractor does not have data on climate tests in this area, then an approach must be developed to assess the resistance of coatings. This paper describes a calculation and experimental technique for assessing the durability of a zinc coating. The methodology is based on the analysis and processing of existing data on the resistance of zinc coatings in various areas with a marine climate and on the results of accelerated tests in a salt fog chamber. The ratios of corrosion rates of coatings obtained in the course of fullscale and accelerated laboratory tests make it possible to calculate the acceleration coefficient. This coefficient allows to get the predicted life of the zinc coating in a particular area of operation with a marine climate. This approach allows to reduce the time to obtain the predicted service life of the coating with the selected thickness.

To verify the reliability of the proposed method for predicting coatings deposited on steel products by hot dip galvanizing, we studied galvanized samples that underwent full-scale climatic tests directly at the site of construction of the facility during the year.

In order to confirm the similarity of the development of corrosion processes in zinc coatings during accelerated tests in salt fog chamber and in the marine climate, metallographic studies of the structure of coatings were carried out.

\section{Experimental}

For testing were prepared carbon steel plates $100 \times 50 \times$ $3 \mathrm{~mm}$ in size with a coating thickness of $120 \mu \mathrm{m}$ deposited by hot dip galvanizing. Laboratory tests to determine the corrosion rate were carried out in a salt spray chamber. The temperature inside the chamber was $(35 \pm 2){ }^{\circ} \mathrm{C}$. The composition of the test solution corresponded to the average composition of the sea water of the Kerch Strait between the Sea of Azov and the Black Sea. The test duration was $72,240,480,720,1440$ hours. Field tests

\footnotetext{
* Corresponding author: kovalev.ma@edu.spbstu.ru
} 
were carried out at the facility under construction, in the open air, for 1 year, with sampling every 3 months. The calculation of the corrosion rate during laboratory and field tests, in microns/year.

Metallographic analysis of the samples was carried out using a Reichert-Jung MeAF-3A optical microscope at magnifications up to $\times 500$. The microstructure was etched using a $4 \%$ solution of HNO3 in ethanol.

\section{Test results}

\subsection{Data analysis of zinc coatings corrosion rates}

During analyzing literature data, the results of zinc coatings field tests in various climatic zones were studied. Table 1 shows the data on the corrosion loss of zinc coatings over 2 years according to test results in 14 different coastal zones, including test data from several climatic regions of the western and eastern US coast, corrosion stations on the coast of Panama, the Philippines and England. Also, in this table is the estimated durability of the coating at a thickness of 100 microns [2].

Table 1. Zinc coating corrosion rate over 2 years of testing in 14 coastal zones

\begin{tabular}{|c|c|c|}
\hline Test place & $\begin{array}{l}\text { Corrosion } \\
\text { rate, } \mu \mathrm{m} / \text { year }\end{array}$ & $\begin{array}{l}\text { The durability of } \\
\text { the coating is } 100 \\
\mu \mathrm{m} \text { thick, years }\end{array}$ \\
\hline Fort Amidor & 0,7 & 150 \\
\hline Miraflores & 1.2 & 80 \\
\hline Cape Kennedy & 1,2 & 80 \\
\hline Manila & 1,5 & 65 \\
\hline $\begin{array}{l}\text { Point Reyes, } \\
\text { California, }\end{array}$ & 1,6 & 60 \\
\hline Daytona Beach, & 2,1 & 45 \\
\hline Kew Beach & 2,1 & 45 \\
\hline Lemon Bay & 2,7 & 35 \\
\hline Danteness & 3,7 & 27 \\
\hline $\begin{array}{l}\text { Cape Kennedy, } 55 \mathrm{~m} \\
\text { from the ocean, } 9 \mathrm{~m} \\
\text { high, }\end{array}$ & 4,1 & 24 \\
\hline $\begin{array}{l}\text { Cape Kennedy, } 55 \mathrm{~m} \\
\text { from the ocean, } \\
\text { ground level, }\end{array}$ & 4,3 & 23 \\
\hline $\begin{array}{l}\text { Cape Kennedy, } 55 \mathrm{~m} \\
\text { from the ocean, } 18 \\
\mathrm{~m} \text { high, }\end{array}$ & 4,5 & 22 \\
\hline $\begin{array}{l}\text { Kew Beach, } 24 \mathrm{~m} \\
\text { from the sea, }\end{array}$ & 6.5 & 15 \\
\hline Galeta Point & 15,9 & 6 \\
\hline
\end{tabular}

For items 1 to 9, tabel 1 shows that, despite high average annual temperatures, the corrosion rate in these places does not exceed 4 microns. This is due to the fact that, on these coasts, the amount of precipitation during the tests was insufficient to wash off the protective layers of corrosion products in the form of carbonic salts and zinc oxides [3]. However, the corrosion rate of the zinc coating at Galeta Point Beach, Panama was about 16 microns due to the fact that the samples were located directly at the surface of the water. In this case, the tests were carried out with alternating wetting with sea water, and not in a marine atmosphere. Under such test conditions, the corrosion rate of the zinc coating is 10-25 microns [2]. Therefore, in the proposed approach to assessing the durability of zinc coatings, data of Table 1 (pos. 10-13) was taken, which are as close as possible to the $\mathrm{C} 5 \mathrm{M}$ marine climate of interest, which indicate corrosion rates of 1-6.5 $\mu \mathrm{m} /$ year [4].

\subsection{Results of laboratory and field tests}

In the process of testing samples in CCT, dense corrosion products formed on the coating, distributed unevenly over the surface of the samples (Fig. 1)
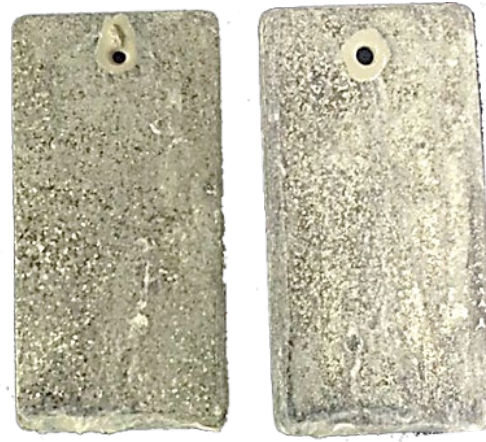

Fig. 1. Samples after salt spray test

Fig. 2 and Table 2 show the results of a change in the corrosion rate of zinc coatings depending on the duration of tests in the salt spray chamber.

Table 2. Corrosion rates of samples after salt spray test

\begin{tabular}{|c|c|c|}
\hline № & $\begin{array}{c}\text { Exposure } \\
\text { time, } \\
\text { hours }\end{array}$ & $\begin{array}{c}\text { Average } \\
\text { corrosion } \\
\text { rates } \mu \mathrm{m} / \\
\text { year }\end{array}$ \\
\hline 1 & 72 & 110 \\
\hline 2 & 240 & 79 \\
\hline 3 & 480 & 35 \\
\hline 4 & 720 & 34 \\
\hline 5 & 1200 & 24 \\
\hline 6 & 1440 & 18 \\
\hline 7 & 2160 & 15 \\
\hline
\end{tabular}

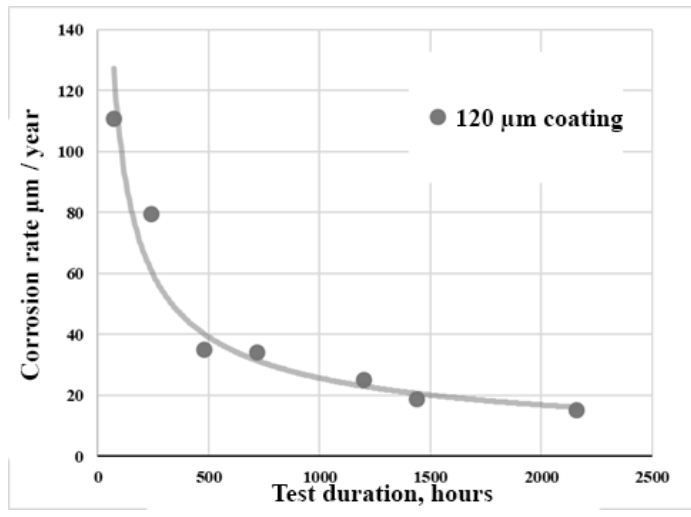

Fig. 2. Evaluation of zinc coating corrosion rates during the test period in salt chamber 
According to the test results, it was found that the corrosion rate drops from $120 \mu \mathrm{m} /$ year to $20 \mu \mathrm{m} /$ year with exposure from 72 to 1440 hours.

With an increase in shutter speed up to 2280 hours, it remains almost unchanged. This can be explained by the formation of corrosion products that prevent the corrosion medium from accessing the coating and slow down the dissolution of the zinc coating.

On the surface of the samples after field testing, there are no visible corrosion products. Some samples retained their metallic luster, but local corrosion damage in the form of gray dots can be detected on the surface (Fig. 3).
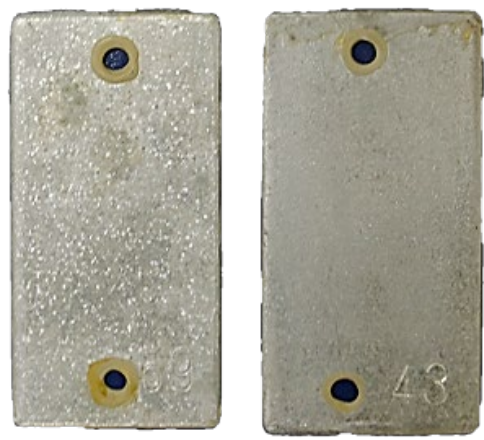

Fig. 3. Samples after field test

The corrosion rates obtained after field tests are presented in Table 3 and Fig. 4.

Table 3. Corrosion rates of samples after field test

\begin{tabular}{|c|c|c|}
\hline № & $\begin{array}{c}\text { Exposure time, } \\
\text { hours }\end{array}$ & $\begin{array}{c}\text { Average corrosion rates } \mu \mathrm{m} \\
\text { / year }\end{array}$ \\
\hline 1 & 1440 & 3,54 \\
\hline 2 & 2880 & 1,89 \\
\hline 3 & 3600 & 1,65 \\
\hline 4 & 8760 & 0,63 \\
\hline
\end{tabular}

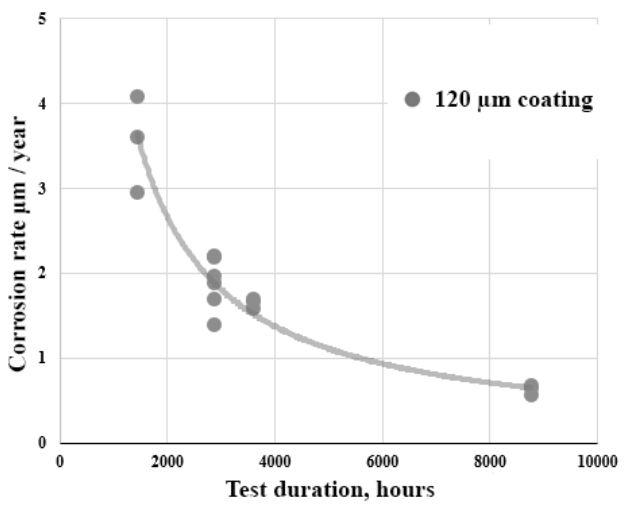

Fig. 4. Evaluation of zinc coating corrosion rates during the field test

Metallography research were carried out in the initial samples state, after accelerated laboratory tests in the salt spray chamber and field climatic tests. The structure of a $120 \mu \mathrm{m}$ thick zinc coating deposited on carbon steel shown at Fig.5. The difference in the structure of the coating is clearly seen, which is associated with the formation of phases of different structure and composition during hot galvanizing $[1,5,6]$

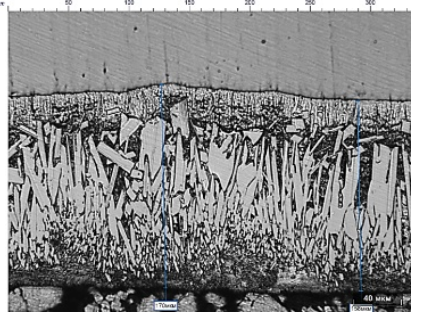

Fig. 5. The microstructure of the zinc coating in the initial state

After 72 hours of laboratory testing, single lesions with a depth of 20-30 $\mu \mathrm{m}$ were detected in the salt spray chamber (Fig. 6a). With an increase in the test time on samples tested in salt spray chamber for 1200 hours or more, the number and area of pits in the coating increase, while the depth of pits remains at about the same level-20-30 microns (Fig. 6a, b)

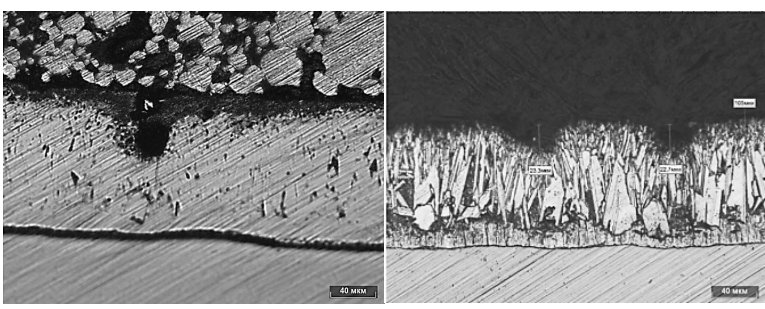

a)

b)

Fig. 6. Corrosion damage in the zinc coating after 72 hours (a) and after 1200 hours (b) of tests in the salt spray chamber

Metallography research were also carried out for the corrosion damage resulting from field tests (Fig. 7).

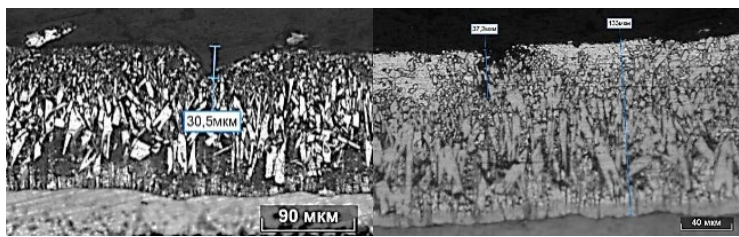

a)

b)

Fig. 7. Coating structure after 2880 hours (a) and after 8760 hours (b) of field test

During the field tests, corrosion damage has a depth of about $30 \mu \mathrm{m}$ and a characteristic relief similar to that shown in a salt spray chamber. During field tests for 8760 hours (1 year), there was also no significant increase in the depth of the resulting pitting damage.

The expected corrosion rate at the place of intended use of the product should be in the range of 4.1-6.5 $\mu \mathrm{m}$ /year. Such data were obtained in the analysis of data obtained from literary sources.

According to the results of laboratory tests in the salt spray chamber, it was found that after 720 hours of exposure, the corrosion rate of the zinc coating is 30$35 \mu \mathrm{m} /$ year and subsequently remains unchanged up to 3 months of testing.

The formula (1) allows to calculate the life of the coating in real conditions, where $\mathrm{T}$ is the durability, $\mathrm{g}$; 
$\mathrm{K}$ is the acceleration coefficient; $\delta$ is the coating thickness, $\mu \mathrm{m}$; $\mathrm{V}$ is the coating corrosion rate established after one month of testing in the salt spray chamber, $\mu \mathrm{m}$.

$$
T=K *\left(\frac{\delta}{V y}\right)
$$

Using the obtained acceleration coefficient, it can be predicted that a zinc coating with a thickness of $120 \mu \mathrm{m}$ should provide protection for steel products for a period of at least 30 years. Literature data give a forecast of 41 years excluding the correction factor.

Conducted one-year field climatic tests of coatings in the area of the intended use of galvanized products, showed comparable with the predicted corrosion rates of coatings, which confirms the validity of the chosen approach. To confirm, and also if necessary, clarify such a forecast, it is advisable to conduct full-scale climatic tests of zinc coatings at the place of their application.

\section{Conclusions}

1. Based on a set of tests and studies, a methodology for assessing the durability of zinc coatings with a relatively short laboratory test period is proposed.

2. It is shown that the corrosion mechanism of the hot dip galvanizing coating during field tests is similar to the mechanism of corrosion of the zinc coating in salt spray chamber in laboratory tests

3. Comparison of laboratory and field tests, as well as metallographic studies of the structure and development of corrosion defects showed that the corrosion mechanism of the HC coating is the same. In both cases, pits with a depth of 20-30 $\mu \mathrm{m}$ are formed on the coating surface of the studied samples, which are formed in the upper layer. With an increase in the duration of testing, the depth of corrosion damage does not increase, their number increases.

The proposed method allows predicting the durability of the zinc coating under operating conditions. The calculation of the durability of a zinc coating with a thickness of $120 \mu \mathrm{m}$ showed a minimum work life for 30 years. This approach to assessing the coating durability reduces the time of laboratory and field tests, which allows to accelerate the commissioning of the structure and reduce the cost of field tests.

\section{References}

1. E. Proskurkin, Protective zinc coatings for harsh corrosion-erosion operating conditions. Territory neftegaz, 9, 42-52, (2007)

2. L. Schreier, Corrosion, M.:Metallurgy, 632 (1981)

3. C. Slunder, W. Boyd, Zinc:Its Corrosion Resistance, Zinc Development Association (1971)

4. A. Lutsenko, M. Kursk, A. Laptev, Substantiation of the terms of full-scale climatic tests of metallic materials in the atmosphere of the Black Sea coast. Questions of materials science,. 87, 126-136, (2016)
5. E. Proskurkin, Protective coatings - quality and durability of pipes. National Metallurgy, 5, 68-78, (2003)

6. P. Maas, Handbook of Hot-dip Galvanization, 494, (2011) 